There is also some relation between the activity of the mud volcanoes and the height of the river. The explanation is that during rains the ground-water presses on the petroliferous sands, and it is noteworthy that the main bed of oil-sand is found at about the level of high-water of the river.

Some signs of exhaustion in the oil-field are noticed by the author, but it is possible that further productive beds may be found by boring. H. B. W.

\section{EXPERIMENTS ON THE WORKING OF GAS-ENGINES.}

A GENERAL meeting of the Institution of Mechanical Engineers was held last week, when the President, Mr. Samuel W. Johnson, delivered an inaugural address dealing chiefly with the progress of locomotive engineering on the Midland Railway, of which he is chief mechanical engineer. The most interesting feature in the ordinary proceeding was the discussion of the first report to the Gas-Engine Research Committee of the Institution. The author of the report was Prof. Frederick W. Burstall, under whose superintendence the investigations had been carried out. The object of the experiments was to determine the effect praduced upon the economy of gas-engines by altering one or more of the conditions which governed their working. In in. ternal combustion engines there are a much larger number of factors to consider than in steam-engines, and it is difficult to ascertain where to look for economy. The factors to be considered are the amount of compression, the speed, the ratio of air to gas, and the amount of heat which is to be ejected through the walls of the cylinder. An increase of compression, for example, is often regarded as conducive to more economical results; but it is uncertain whether the attendant increase in economy is really due to compression alone. To ascertain this, the conditions of working should be altered successively one at a time. This has been done for the steam-engine, but all published results of tests made on gas-engines are based upon only one fixed set of conditions.

A small engine was used by the committee, but was one specially constructed for experimental purposes. Small size was an advantage, inasmuch as it allowed measurements, such as those of volumes of air, to be made with accuracy. The work of the committee appears to have been undertaken with commendable care, and a precision was aimed at more typical of the physical laboratory than of ordinary engineering experiments. This is particularly noticeable in the arrangement of the apparatus and methods of calibration. followed. It would take far too much space to follow these in detail, interesting and instructive as they are to engineers, and we can only hope to give a partial idea of the methods followed. This report, it should be remenbered, is but introrluctory to the description of the actual work of testing, most of which has yet to be undertaken. As the author stated, experimental work is often compromised by being carried out with instruments upon the arcuracy of which no information is furnished. When a comparison is nade of a number of results, it is always difficult to discover how far differences are due to working conditions or to inevitable experimental error. In purely physical experiments, the report continued, accuracy may be obtained to the degree of one part in a thousand; in a few special cases, even better results may be reached. In an engineering experiment it is hopeless to expect such accuracy, owing to the great diffi. culty of keeping the working conditions sufficiently steady from beginning to end of the experiment. With ordinary care, and the use of appliances which are found in all works, probably all that can be expected is to get results correct to 3 or 4 per cent. With special care, half of I per cent. may be reached; but the author does not suggest that all the results of the experiments made by the committee have this high degree of accuracy, but in the pripcipal measurements probably the experimental error involved does not in any case exceed 1 per cent.

The engine used was of 2-horse nominal power, capable of developing a maximum of 5 I.II.P. ; it has a 6-inch cylinder and 12-inch stroke. The valves are worked in the ordinary manner there is an ordinary Watt governor acting on a small roller, and causing a charge of gas to be cut off when the speed is too high. To effect changes in compression the connecting-rod is made so that its length can be varied. Compressions employed in the experiment varied between 35 and $90 \mathrm{lbs}$. per square inch ; variation in the amount of gas admitted was effected by throttling. For measuring the supply of gas a calibrated holder was used ; the wet test meter being discarded, as it does not control the fluctuations of pressure in the mains. By this instrument accuracy to the extent of one-tenth of I per cent. was obtained ; calibration was effected by means of a standard cubic foot measure. To determine the air supply per stroke, a neter was used in place of trusting to the usual method of calculation. The arrangement followed was practically that employed by Dr. A. Slaby, of Berlin. The meter employed was a 400 -light standard wet meter made by Alexander Wright and Co., of Westminster. Air is passed in by a blower, the pressure being kept constant by a governor. After passing through the meter the air is delivered into a safety-box, which is used to prevent inflammable gas from passing back into the meter, and also to give relief in case of back ignition. A rubber-bag is used to prevent fluctuations in the meter during the suction stroke. The direct measurement of air supply is usually considered a diff. cult and dangerous undertaking; but the author stated that no trouble had been found with this portion of the apparatus. The air neter was checked by blowing air through it into the gasbolder, and was found to be correct to the half of I per cent.

The amount of heat passed into the jacket was measured by running all the cooling water for a single test into a tank, and taking the temperature by means of thermometers. Samples of exhaust gases were taken and analysed. In this detail the great difficulty is not in making the analysis, but in obtaining a true sample. A single bubble of gas was taken from just below the exhaust valve after each explosion. The apparatus for doing this was illustrated by means of wall diagrams, which showed that the object aimed at was obtained by an electrical relay which actuated a small needle valve that allawed a single bubble of gas to be sucked into the gas receiver. Power [developed was ascertained by a Wayne indicator; an instrument found superior to others tried. Prof. Burstall states that it is in careful hands, apparently the most accurate indicator of the present time. It has a rotating piston in place of the ordinary reciprocating piston. This piston does not touch the containing cylinder at its outer extremities, but is guided at the centre on circular bearings. In this way friction is small and not liable to change, because the bearings can be well lubricated. There are many interesting points about its mechanism which were described in the report. Thin sheets of smoked mica are used in place of the ordinary metallic faced paper or "cards." This device is highly spoken of by those who have had experience in its use.

As the engine was not fitted with a timing valve-a device which the author considers absolutely necessary to all sizes of gas-engines-it was decided to attempt to ignite the charge by means of an electric spark, and it was hoped that electric ignition would prove more certain than any form of hot-tube igniter. This, however, did not prove to be the case; and not the least interesting part of the report is contained in the dis. cussion of the failure in this detail. The rope-break used was of the ordinary kind, having dead weights on the lower end of the rope and a spring balance at the upper end. A Harding counter for ascertaining the number of revolutions was employed, and analyses of the coal-gas were made by Mr. G. N. Huntly, who also supervised the analyses of the exhaust gas. The results of seventeen preliminary experiments made were given in a table contained in the report, and on copies of indicator diagrams attached. The mechanical efficiency of the engine varied from 76 to 84 per cent., the mean value of the whole seventeen tests being 81 per cent. It must be remembered, however, that these experiments are, as stated, preliminary, and, it may be added, they have been carried out under circumstances of exceptional difficulty, which conditions, however, will not recur. The report states that it would seem probable that the influence of increased compression on economy is due to the fact that weaker charges can be burnt completely during the stroke when the compression is high. The tests seem to indicate, the report continues, that economy depends on the choice of the correct ratio of air to gas; and this ratio increases with the com. pression. The number of experiments, however, are, as the report states, not yet sufficient to determine what this ratio is for any given compression. It is intended to make a series of tests sufficient for determining this important point. Further experiments are to be made at a constant speed ; the variables being the load, the ratio of air to gas, and the compression. It is

NO. I 488 , VOL. 58 ] 
stated that, so far as these additional experiments have been carried, the first results have been borne out in regard to the advantage of using a suitable mixture, and in showing the importance of making an accurate analysis of the exhaust gases.

The discussion which took place on the presentation of the report did not add materially to information on the subject, Some of the criticisms were very wide of the mark, more especially in regard to one point, upon which much stress was laid, viz. the leakage of gas through the indicator. This was supposed by some speakers to be sufficient to vitiate the value of the experiments, but, according to Prof. Burstall's tests, made in order to clucidate this point, the consumption of gas by the indicator was so minute as to be imperceptible. It was stated during the discussion by Mr. Burstall, a brother of the author, that, according to calculation, if diagrams were taken every five minutes, when running at 200 revolutions, and if the whole of the gas escaped on the stroke, the loss would be one-fiftieth of I per cent.

\section{UNIVERSITY AND EDUCATIONAL INTELLIGENCE.}

Cambridge. - A combined examination of non-resident candidates for open scholarships, exhibitions, \&c., will be held at Trinity College, Clare College and Trinity Hall, beginning on November I. At Trinity College there will be offered for competition about ten scholarships, about ten exhibitions, and about three sizarships. Scholarships include (I) major scholarships, of the value of $80 \%$. a year, (2) minor scholarships, of the value of $75 \%$ a year or of $50 \%$. a year. Exhibitions are generally of the value of $40 \mathrm{l}$. a year. Scholarships and exhibitions are tenable for two years from the commencement of residence. Sizarships are of the value fof about $100 /$. a year (namely, a payment in money of $80 \%$, and a remission of College fees and dues to the extent of about $20 \%$.). They are tenable until the expiration of nine terms from the commencement of residence, unless the holder is previously elected to a major scholarship. Candidate's for sizarships must send satisfactory evidence to one of the Tutors that they are in need of the assistance given to sizars. The subjects of examination will be classics, mathematics, natural sciences, moral sciences, and history. A candidate may take any one of these subjects, or any combination of subjects so far as the arrangement of the papers in the examination permits. At Clare College about eight scholarships of values varying from $80 \%$. to $40 \%$, and at Trinity I Iall six scholarships at least, ranging between the same values, will be awarded. These scholarships are offered for proficiency in classics, or mathematics, or natural science, or history. Deserving candidates who do not lattain the standard for these scholarships may be awarded exhibitions of the annual value of $30 l$. Forms of application for admission to the examination may be obtained from any of the Tutors of the Colleges named.

IN the IIouse of Commons on Thursday, in reply to a question whether it was the intention of the Government to take the second reading of the London University Commission $13 i l l$ before Whitsuntide, Mr. Balfour said he conld not give any definite promise in view of the present state of public business, but he would not discourage the hope that they might have a chance of reaching the Bill as early as some time before Whitsuntide.

A Parliamentary paper issued by the Science and Art Department states that the total amount expended ron technical education during the year $1895^{-96}$ in the United Kingdom was $787,467 l$, and that the estimated total expenditure for the year 1896-97 was $847,62 \mathrm{cl}$., exclusive of the sums allocated to tech nical education under the Welsh Intermediate Education Act, 1889. The total amount of the residue received uncler the Local Taxation Act by crunties and county boroughs in England in $1895-96$ was $775,944 l$., of which $616,607 l$. was appropriated to educational purposes, and $159,336 \%$. to relief of rates, the latter sum including $12 \mathrm{I}, 558 \mathrm{l}$. devoted by the London County Council to that purpose. In Wales the whole of the residue grant of $37,236 \%$. paid to thirtcen countics and three county boroughs is devoted to intermediate and technical education. The amount of residue received by Scottish authorities was $38,262 l$., of which $28,999 l$. was apportioned to technical educa. tion, and 91581 . to relief of rates. In Ireland the residue is not applicable to technical education, but eleven local authorities are making grants out of the rates for that purpose.

NO. I 488, VOL. 58 ]

\section{SCIENTIFIC SERIALS.}

American Journal of Mathematics, vol. xx. No. 2.-On the focal surfaces of the congruences of tangents to a given surface, by $A$. Pell. 'This paper is based upon two theorems given by Darboux ("Théorie générale des Surfaces," vol. iii. p. I2I) and Kœnigs ("Sur les propriétés infinitésimal de l'espace réglé"), viz.: the locus of the centres of geodesic curvature of lines of curvature of any surface is the edge of regression of the developable surface, generated by the tangent planes of the surface at all points of the lines of curvature, and the edges of regression of the developable surfaces of a congruence form two families of curves on the focal surfaces (say $S_{A}$ and $S_{B}$ corresponding to the focal surfaces $\mathrm{A}$ and $\mathrm{B}$ ), the osculating planes of which are tangent to the surfaces $B$ and $A$ respectively, and the points of contact describe on these surfaces two families of conjugate lines $S_{A}$ and $S_{B}$. Other theorems discussed are due to $T$. Caronnet (Comptes rendus, 1892), E. Cosserat (C.R., 1894) and A. Demoulin (C.R., 1894).-Displacements depending on one, $\mathrm{t}$ wo and three parameters in a space of four dimensions, by $T$. Craig. This is a concise generalisation to a space of four dimensions of the kinematical methods developed by Darboux in the first two volumes of his "Théoric générale des Surfaces." The author em. ploys Poincaré's nomenclature ( $c f$. "Sur les résidus des intégrales doubles," Acta Math., t. 9, p. 385).-Further researches in the theory of quintic equations, by Emory McClintock. The paper contains four parts. The first part is a preliminary classification of quintics into reducible and irreducible, and again into resolvable and unresolvable quintics. The second is a simplified restatement of the author's earlier discoveries. The third contains a presentation of the necessary form of the coefficients of the general resolvable quintic; and the last part is occupied with the development of a theorem according to which any given resolvable quintic engenders another for which the author's sextic resolvent has the same rational value. The menoir was read at the Toronto meeting of the American Mathematical Society in August last.

Symons's Monthly Meteorological Magazine, April.-The climate of Paris, by M. J. Jaubert. This is an account of an interesting and useful book by the meteorologist of the Montsouris Observatory, compiled from all available sources in the Paris district. The mean temperature at the National Observatory is $51^{\circ} \cdot 3$, but in the suburbs it is less, e.g., Parc St. Maur, $50^{\circ} \circ$. The lowest temperature recorded in the neighbourhood was $-17^{\circ} \cdot 5$, in December 1871 , and the highest was $101^{\circ} \cdot 1$ in 1874 and $188 \mathrm{r}$. Fogs are rather frequent, alout forty in a year, but a foggy day is defined as one on which objects at a distance of a mile cannot be distinguished. The mean rainfall is about 22 inches, but the amount varies in different parts of the city. About thirty thunderstorms occur in a year, mostly in summer. Very little hail falls, and the stones are seldom more than of an inch in diameter. The yearly average amount of cloud is 6.0.- Results of meteorological observations at Camden Square for forty years, $18 ; 8-97$. The average rainfall was $I 71$ inches; the amount last March was 1.46 inches. The mean of all the highest shade temperatures was $61^{\circ} \cdot 9$, and the mean of all the lowest minimum temperatures was $25^{\circ} 3$. In March last the absolute extremes were $59^{\circ} \cdot \mathrm{I}$ and $25^{\circ} \mathrm{I}$, while the temperature on the grass fell below freezing point on twenty-four nights.

Bollettino della Societì Sismologica ltaliana, vol. iii. No. 7 - Some modifications of the doubly sensitive electric seismoscope, and instructions for its installation and working, by $G$. Agamennone. - The seismic recorder with increased velocity on the occasion of the earthquake of September 21,1897 , by P. Tacchini. - Diurnal movement of the obelisk of Washington, by $\mathrm{E}$. Oddone. - Notices of earthquakes recorded in Italy (May 14-23, I897), the most important being an elaborate account of the earthquake of the Tyrrhenian Sea on May I5.

\section{SOCIETIES AND ACADEMIES. LONDON.}

Royal Society, March IO.-." On the Rotation of Plane of Polarisation of Filectric Waves by a Twisted Structure." By Jagadis Chunder Bose, M.A., D.Sc., Professor of Phy'sical Science, Presidency College, Calcutta. Communicated ly Iord Rayleigh, F.R.S.

"On the Production of a 'Dark Cross' in the field of Electro. magnetic Radiation." By Jagadis Chunder Bose, M.A., D. Sc. Protessor of Physical Science, Presidency Collcge, Calcutta. Communicated by Lord Rayleigh, F.R.S. 